\title{
Simplified Dosing of Gentamicin for Treatment of Sepsis in Bangladeshi Neonates
}

\author{
M. Monir Hossain', Nazma A. Chowdhury', Mahfuza Shirin', Samir K. Saha², Mary Miller-Bell², \\ David Edwards ${ }^{4,5}$, Jacob Aranda ${ }^{5}$, Patricia Coffey ${ }^{6}$, and Gary L. Darmstadt ${ }^{7}$ \\ 'Department of Neonatology and 2Department of Microbiology, Bangladesh Institute of Child Health, Dhaka Shishu (Children's) \\ Hospital, Dhaka 1207, Bangladesh, ${ }^{3}$ Department of Pharmacology, Duke University, Durham, NC, USA, ${ }^{4}$ Department of \\ Pharmacy Practice, Wayne State University, Detroit, MI, USA, ${ }^{5} \mathrm{NIH} / \mathrm{NICHD}$ Pediatric Pharmacology Research Unit Network, \\ Children's Hospital of Michigan, Wayne State University, Detroit, MI, USA, 'PATH, Seattle, WA, USA, and ${ }^{7}$ International Center \\ for Advancing Neonatal Health, Department of International Health, Bloomberg School of Medicine, Johns Hopkins University, \\ Baltimore, MD 21205, USA
}

\begin{abstract}
Extended-interval dosing of gentamicin has several advantages over conventional multiple-daily dosing for the treatment of sepsis. The study was conducted to evaluate the pharmacokinetics of gentamicin for the treatment of neonatal sepsis in predetermined doses at 24- or 48-hour intervals, according to weight category, and to develop a simplified protocol for use in peripheral healthcare settings in developing countries. This prospective observational study was conducted among 59 neonates admitted to the Special Care Nursery at Dhaka Shishu Hospital, Bangladesh, with suspected sepsis and treated with antibiotics, including gentamicin. Intravenous dosing of gentamicin according to weight category was: $10 \mathrm{mg}$ every 48 hours if the infant weighed $<2,000 \mathrm{~g}(\mathrm{n}=23), 10 \mathrm{mg}$ every 24 hours if the infant weighed 2,000-2,249 $\mathrm{g}(\mathrm{n}=12)$, or $13.5 \mathrm{mg}$ every 24 hours if the infant weighed 2,500-3,000 $\mathrm{g}(\mathrm{n}=24)$. Peak and trough concentrations of gentamicin and the presence of signs of nephrotoxicity and ototoxicity were determined. The mean \pm standard deviation peak concentration of gentamicin was $12.3 \pm 3.7 \mu \mathrm{g} / \mathrm{mL}$ in infants weighing $<2,000 \mathrm{~g}, 9.6 \pm 3.1$ $\mu \mathrm{g} / \mathrm{mL}$ in infants 2,000-2,249 g, and $10.0 \pm 3.4 \mu \mathrm{g} / \mathrm{mL}$ in infants 2,500-3,000 g. Initial peak concentration of gentamicin was $>12 \mu \mathrm{g} / \mathrm{mL}$ in $28.8 \%$ and initial trough concentration was $>2 \mu \mathrm{g} / \mathrm{mL}$ in $6.8 \%$ of the subjects. No signs of nephrotoxicity or ototoxicity were detected. Favourable pharmacokinetic parameters found with the simplified dosing regimen suggest that it is safe for the treatment of neonatal sepsis.
\end{abstract}

Key words: Aminoglycoside; Antibiotics; Gentamicin; Infection; Newborns; Observational studies; Pharmacokinetics; Prospective studies; Sepsis; Bangladesh

\section{INTRODUCTION}

An estimated 20\% of all children born in developing countries acquire an infection during the neonatal period, and infectious diseases account for ap-

Correspondence and reprint requests should be addressed to:

Dr. Gary L. Darmstadt

Director

International Center for Advancing Neonatal

Health

Department of International Health E-8153

Bloomberg School of Medicine

Johns Hopkins University

615 North Wolfe Street

Baltimore, MD 21205

USA

Email: gdarmsta@jhsph.edu

Fax: 410-614-1419 proximately one-third of all neonatal deaths $(1,2)$. Many neonatal deaths can be averted if the signs of infection could be recognized early by caregivers and first-line health workers and the disease is treated promptly (3-8).

Gentamicin is a potent aminoglycoside antibiotic with bactericidal activity against Gram-negative bacteria. Among the causative agents of neonatal sepsis, Gram-negative pathogens play a crucial role, and gentamicin is the drug of choice for first-line management. On the basis of the large volumes of distribution and slow renal clearance of aminoglycosides in neonates, larger doses based on body-weight, administered at longer intervals, are advantageous (9-12). To treat neonatal sepsis more effectively in low-resource settings, it is necessary to develop a strategy for extended-interval dosing of 
gentamicin, i.e. 24 hours or more in between doses since more frequent contact with a health worker is often not feasible.

Based on the evidence that extended-interval dosing of gentamicin has many advantages over more frequent-interval dosing regimens, we aimed at evaluating extended-interval dosing regimens for gentamcin, which were developed based on issues of pharmacokinetics, safety, frequency of dosing, body-weight of the patient, and acceptability as described previously $(13,14)$. Here, we report pharmacokinetic and safety evaluation results from the Bangladesh site of a two-site study reported elsewhere (13).

\section{MATERIALS AND METHODS}

\section{Patients}

The study was conducted in Dhaka Shishu (Children's) Hospital, a major medical centre for children in South Asia, in the Neonatal Special Care Nursery where out-born neonates are admitted. We initially aimed at enrolling 20 patients weighing $<2,000 \mathrm{~g}, 10$ patients weighing 2,000-2,240 g, and 20 patients weighing 2,500-3,000 g with guidance on total enrollment from the study's Data Safety Monitoring Board, which regularly reviewed progress of the trial, with an aim to ensure safety of patients. Neonates up to 28 days of age, who were admitted from 15 February to 15 June 2003 for the treatment of suspected or culture-proven neonatal sepsis, were included in the study (Fig.). Neonates with major congenital anomalies, haemodynamic instability, or compromised renal function were excluded. Once a potential participant was identified, a parent was counselled in the presence of a senior staff nurse, and informed written consent was obtained. The Ethical Review Committee at the Bangladesh Institute of Child Health, the Committee on Human Research at the Johns Hopkins Bloomberg School of Public Health, and the PATH Human Subjects Protection Committee approved the protocol. All unexpected adverse events were reported to the appropriate authorities within 24 hours. The study was registered at clinicaltrials.gov (\#H.22.02.08.30.B1).

\section{Gentamicin-dosing and monitoring}

All patients received standard clinical management of sepsis, which included use of additional antibiotics in combination with gentamicin to provide broad-spectrum coverage as indicated based on available clinical and laboratory data. Neonates were enrolled into different weight categories and

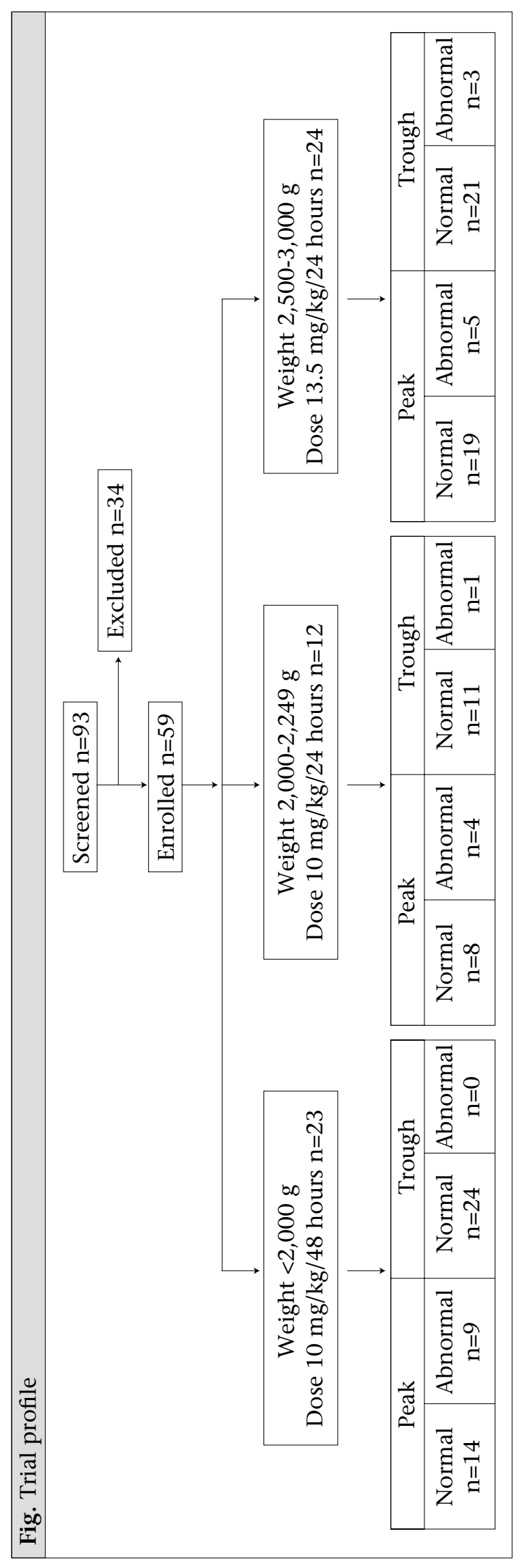


received a fixed dose and frequency of administration of gentamicin specific for each weight category (Fig. and Table). The rationale for selection of these dosing-interval regimens has been reported previously $(13,14)$. Patients weighing 2,250-2,499 g were not included in the study because extended-interval dosing regimens of gentamicin, which reliably produce favourable pharmacokinetics, are already available, and further testing was, thus, not warranted.

The dose was pushed intravenously over a 30-second period, followed by a flush with $0.5 \mathrm{~mL}$ of normal saline. For monitoring trough concentrations of gentamicin, blood was obtained 30 minutes prior to the administration of the third dose, and the peak level was monitored in serum separated from blood collected one hour after the administration of the third dose. Since renal excretion of gentamicin is slower in low-birthweight (LBW) babies, the safety of administration in patients with very LBW, weighing $<2,000 \mathrm{~g}$ was further ensured by giving the doses only at 48-hour intervals. The monitoring strategy for these babies was modified so that the serum level of drug was available as early as possible. Thus, serum levels were obtained 2 and 24 hours after the first dose of gentamicin rather than the trough and peak levels around the third dose as for patients weighing $\geq 2,000 \mathrm{~g}$. Serum levels of gentamicin were measured by chemiluminescent assay with Immulite 2000 (Diagnostic Products Corporation, Los Angeles, CA). Pharmacokinetic indices, including peak and trough levels of genatmicin, were determined as described previously (13).

For infants weighing $\geq 2,000 \mathrm{~g}$, whenever abnormal gentamicin trough levels were detected, i.e. $>2 \mu \mathrm{g} / \mathrm{mL}$, the dosing-interval was extended from 24 to 48 hours. If the peak concentration was $>12$ $\mu \mathrm{g} / \mathrm{mL}$, the dose was decreased by $10-15 \%$, and if the peak was $<4 \mu \mathrm{g} / \mathrm{mL}$, the dose was increased by
10-15\%. Whenever dose modifications were made, repeat gentamicin levels were determined 48 hours later.

Blood samples were collected from 23, 12, and 24 patients in the three weight categories: $<2,000 \mathrm{~g}$, 2,000-2,249 g, and 2,500-3,000 g respectively. Haemoglobin concentration, serum electrolytes, plasma creatinine, and urine output were monitored during the study period. All the enrolled patients were followed up once for hearing assessment between 6 and 12 weeks of age. Hearing assessment was done by Brainstem Auditory Evoked Response (BAER) testing.

\section{RESULTS}

Of the 59 patients, $30(51 \%)$ were preterm $(<37$ completed weeks of gestation), 46 (78\%) were male, and 29 (49\%) were aged one day. Duration of hospital stay was 2-22 days (mean \pm standard deviation 8.6 \pm 4.2 days). Culture-positive septicaemia was identified in $10.1 \%(6 / 59)$ of the cases. The isolated organisms were Escherichia coli $(\mathrm{n}=2)$, Klebsiella pneumoniae $(\mathrm{n}=1)$, Staphylococcus aureus $(\mathrm{n}=1)$, Salmonella spp. $(\mathrm{n}=1)$, and Haemophilus influenzae $(\mathrm{n}=1)$. Total doses of gentamicin given to patients across the three weight categories ranged from 1 to 10 , and the duration of treatment was 2-10 days (Table).

Initial peak concentrations of gentamicin were $>12$ $\mu \mathrm{g} / \mathrm{mL}$ and $<4 \mu \mathrm{g} / \mathrm{mL}$ in $28.8 \%$ and $1.7 \%$ of the patients respectively (Table). Initial trough concentration was $\geq 2.0 \mu \mathrm{g} / \mathrm{mL}$ in $6.8 \%$ of the cases. Nineteen $(32.2 \%)$ neonates required adjustment of gentamicin dose; nine were in the category of $<2,000 \mathrm{~g}$ and five each were in the categories of 2,000-2,249 $\mathrm{g}$ and 2,500-3,000 g. Nine patients each weighing $<2,000 \mathrm{~g}$ had a high peak level; none had a high trough level. In the category of 2,000-2,249 g, adjustment of dose was needed for three patients for high peak, one for high trough, and one for low

\begin{tabular}{|c|c|c|c|}
\hline \multirow[b]{2}{*}{ Pharmacokinetic parameter } & \multicolumn{3}{|c|}{ Weight category } \\
\hline & $\begin{array}{c}<2,000 \mathrm{~g} \\
(\mathrm{n}=23)\end{array}$ & $\begin{array}{c}2,000-2,249 \mathrm{~g} \\
(\mathrm{n}=12)\end{array}$ & $\begin{array}{c}2,500-3,000 \mathrm{~g} \\
(\mathrm{n}=24)\end{array}$ \\
\hline Dosage of gentamicin (mg) & 10 & 10 & 13.5 \\
\hline Interval of dose (hours) & 48 & 24 & 24 \\
\hline Number of doses & $1-6$ & $3-10$ & $2-10$ \\
\hline Days of treatment & $2-10$ & $3-10$ & $2-10$ \\
\hline Peak concentration (mean $\pm \mathrm{SD}, \mu \mathrm{g} / \mathrm{mL}$ ) & $12.1 \pm 3.6$ & $9.6 \pm 3.1$ & $9.7 \pm 2.9$ \\
\hline Trough concentration (mean $\pm S D, \mu g / m L)$ & $0.4 \pm 0.4$ & $1.6 \pm 1.3$ & $1.4 \pm 1.2$ \\
\hline
\end{tabular}


peak. Five (24.0\%) patients in the group of 2,5003,000 g needed correction; two for both high peak and trough serum concentrations, and three for high peak concentration only.

On enrollment, plasma creatinine level was normal $(<120 \mu \mathrm{mol} / \mathrm{L})$ in $91.4 \%(53 / 58)$ of the patients. At the time of discharge, all the patients, except one (serum creatinine level $169 \mu \mathrm{mol} / \mathrm{L}$ ), including the cases with elevated serum gentamicin peak and/or trough levels, had normal plasma creatinine levels. The frequency of urine output was also normal in $98.3 \%(57 / 58)$ of the cases.

Seven patients died, none of whom had an abnormal serum level of gentamicin. Causes of death included prematurity with septicaemia $(\mathrm{n}=2)$, birth asphyxia with septicaemia $(\mathrm{n}=2)$, and birth asphyxia ( $n=3)$. Three patients left against medical advice, and two of them had an abnormal level of gentamicin. Two patients $(5 \% ; 2 / 40)$ were labelled as impaired for hearing on assessment at 6-12 weeks of age. However, gentamicin levels of all these cases were normal (peak $8.9 \mu \mathrm{g} / \mathrm{mL}$ to $9.7 \mu \mathrm{g} / \mathrm{mL}$, trough $0.1 \mu \mathrm{g} / \mathrm{mL}$ to $2.0 \mu \mathrm{g} / \mathrm{mL}$ ).

\section{DISCUSSION}

This study evaluated the dosing of gentamicin at an interval of 24-48 hours in different weight groups, considering pharmacokinetics and safety. Studies have shown that pharmacokinetics of gentamicin are essentially equivalent following intravenous and intramuscular injections (15). The results of this study, which involved intravenous administration, can be extrapolated to intramuscular injections, the suitable mode to use in the community, including peripheral health facilities, where intravenous access is not available.

Pharmacokinetic data of gentamicin indicate that half-lives are longer in neonates compared to older children (16-18). These data lend support to the recommendation to increase the dosing-interval from 12 to 18 hours up to 24 hours or more. There has been recent interest in extended (e.g. daily or less frequent) dosing of aminoglycosides because higher doses given at longer intervals are likely to improve efficacy and reduce the toxic effects $(9,12,14)$. In a developing country like Bangladesh, once-daily dosing of gentamicin can be used as an important treatment option in neonatal sepsis whereas more frequent dosing is not feasible for use in the community and peripheral health-facility settings $(14,19)$.

In our study, the mean peak concentrations around the third dose in patients weighing 2,000-2,249 $\mathrm{g}$ and 2,500-2,999 g were consistent with other studies of once-daily dosing of gentamicin $(9,11,12,20$ 22). Skopnik compared two groups of neonates who received once- and twice-daily doses of gentamicin and found that the once-daily group did better regarding efficacy and toxicity (21). High peak concentration of aminoglycoside is the major determinant of bacterial killing rather than the minimum inhibitory concentration of the antibiotic $(23,24)$. The target peak concentration of gentamicin is 4$12 \mu \mathrm{g} / \mathrm{mL}$ (25) but 29\% (17/59) of the cases in this study had higher peak values (range 12.1-20.6 $\mu \mathrm{g}$ / $\mathrm{mL}$ ). Nonetheless, all the cases had normal renal function as measured by plasma creatinine level. Further, hearing assessment of 12 of the cases at 612 weeks of age did not reveal any sign of ototoxicity attributable to antibiotic exposure. This is in accordance with previous findings about the safety of higher peak levels of gentamicin (25).

Pharmacokinetic data of gentamicin administration in neonates with very low birthweight indicate that the elimination half-life is longer in preterm compared to full-term neonates (26). Thus, we fixed the initial dose for preterm babies with very low birthweight as $10 \mathrm{mg}$ given every 48 hours. In this weight category, we found a high peak concentration $(>12 \mu \mathrm{g} / \mathrm{mL})$ in more than one-third (39.1\%) of the babies, although their trough concentrations were uniformly normal. Evidence would suggest that the dose used in this weight category will be efficacious (14), and since trough levels were normal, this dose is acceptable.

A low trough concentration of $<2 \mu \mathrm{g} / \mathrm{mL}$ is a desirable goal because aminoglycosides exhibit a marked post-antibiotic effect (persistent suppression of microbial growth after antmicrobial drug exposure ceases), and longer duration of low levels helps prevent the rapid development of microbial resistance (adaptive resistance) and minimizes nephrotoxicity and ototoxicity (27). In the present study, the mean trough concentrations of gentamicin in all the three weight categories were acceptable. The distributions of trough levels were the same as reported in previous studies where gentamicin was given once or twice daily at doses of $4-5 \mathrm{mg} / \mathrm{kg}$ of body-weight per day $(9-12,14,21)$. Our findings are consistent with those of Hayani et $a l$. who showed that trough concentration is not increased if a larger dose is given at a prolonged interval (9). Nephrotoxicity is one of the recognized complications of aminoglycoside therapy. Clinical studies have shown that renal toxicity is less frequent in newborns $(28,29)$; this is due, in part, to the lower rate of renal accumulation of gentamicin 
in neonates (28). In the present study, we had only one neonate with raised plasma creatinine; however, the infant had normal peak $(11.2 \mu \mathrm{g} / \mathrm{mL})$ and trough $(0.1 \mu \mathrm{g} / \mathrm{mL})$ levels of gentamicin. Mulhall et al. showed that the incidence of nephrotoxicity is reduced when the dosing interval is $>18$ hours in neonates (25). Ototoxicity is another potential complication of gentamicin therapy. Hearing assessment at 6-12 weeks revealed only two infants with hearing impairments. However, this did not appear to be attributable to gentamicin therapy as none of the cases had any abnormality in peak and trough levels of gentamicin.

In conclusion, this study of extended-interval dosing of gentamicin, stratified for different weight categories of neonates, indicates that this dosing scheme is simple, adequate, safe, and feasible for the treatment of neonatal sepsis in communities and peripheral health facilities. Such dosages are now being manufactured in pre-filled Uniject ${ }^{\mathrm{TM}}$ (Becton Dickinson) devices and used for the evaluation of safety and acceptability for the treatment of neonatal sepsis at the community level.

\section{ACKNOWLEDGEMENTS}

This study was supported by Save the Children-USA through a grant from the Bill \& Melinda Gates Foundation and by PATH. PATH's contribution to this study was made possible through support provided by the Office of Health, United States Agency for International Development (USAID) under the HealthTech Cooperative Agreement No. GPH-A-0001-00005. The opinions expressed herein are those of the authors and do not necessarily reflect the views of USAID. The authors thank Additional Professor Vinod Paul of All-India Institute of Medical Sciences, Delhi, for serving on the Data and Safety Monitoring Board. The authors also thankfully acknowledge Dr. Shaheen Akter and Dr. Manifa Afreen of Dhaka Shishu Hospital for their technical assistance.

\section{REFERENCES}

1. Lawn JE, Cousens S, Zupan J. Four million neonatal deaths: When? Where? Why? Lancet 2005;365:891-900.

2. Stoll BJ. The global impact of neonatal infection. Clin Perinatol 1997;24:1-21.

3. World Health Organization. Postpartum care of the mother and the newborn: a practical guide. Geneva: World Health Organization, 1998. 81 p. (WHO/RHT/ MSM/98.3).

4. Darmstadt GL, Black RE, Santosham M. Research priorities and postpartum care strategies for the prevention and optimal management of neonatal infec- tions in less developed countries. Pediatr Infect Dis J 2000;19:739-50.

5. Ahmed S, Sobhan F, Islam A, Barkat-e-Khuda. Neonatal morbidity and care-seeking behaviour in rural Bangladesh. J Trop Pediatr 2001;47:98-105.

6. Bang AT, Bang RA, Baitule S, Deshmukh M, Reddy $\mathrm{MH}$. Burden of morbidities and the unmet needs for health care in rural neonates-a prospective study in Gadchiroli, India. Indian Pediatr 2001;38:952-65.

7. Baqui AH, El-Arifeen S, Darmstadt GL, Ahmed S, Williams EK, Seraji HR et al. Effect of community-based newborn-care intervention package implemented through two service-delivery strategies in Sylhet district, Bangladesh: a cluster-randomised controlled trial. Lancet 2008;371:1936-44.

8. Darmstadt GL, Baqui AH, Choi Y, Bari S, Rahman SM, Mannan I et al. Validation of community health workers' assessment of neonatal illness in rural Bangladesh. Bull World Health Organ 2009;87:12-9.

9. Hayani KC, Hatzopoulos FK, Frank AL, Thummala MR, Hantsch MJ, Schatz BM et al. Pharmacokinetics of once-daily dosing of gentamicin in neonates. J Pediatr 1997;131:76-80.

10. Thomson AH, Kokwaro GO, Muchohi SN, English M, Mohammed S, Edwards G. Population pharmacokinetics of intramuscular gentamicin administered to young infants with suspected severe sepsis in Kenya. Br J Clin Pharmacol 2003;56:25-31.

11. English M, Mohammed S, Ross A, Ndirangu S, Kokwaro G, Shann F et al. A randomized, controlled trial of once daily and multi-dose daily gentamicin in young Kenyan infants and children. Arch Dis Child 2004; 89:665-9.

12. Nestaas E, Bangstad H, Sandvik L, Wathne K. Aminoglycoside extended interval dosing in neonates is safe and effective: a meta-analysis. Arch Dis Child Fetal Neonatal Ed 2005;90:F294-300.

13. Darmstadt GL, Hossain MM, Jana AK, Saha SK, Choi Y, Sridhar S et al. Determination of extended-interval gentamicin dosing for neonatal patients in developing countries. Pediatr Infect Dis J 2007;26:501-7.

14. Darmstadt GL, Miller-Bell M, Batra M, Law P, Law K. Extended-interval dosing of gentamicin for treatment of neonatal sepsis in developed and developing countries. J Health Popul Nutr 2008;26:163-82.

15. Chambers HF. Antimicrobial agents: the aminoglycosides. In: Hardman JG, Limbird LE, Gilman AG, editors. Goodman and Gilman's The pharmacological basis of therapeutics. 10th ed. New York, NY: McGraw Hill, 2001:1219-38.

16. McCraken GH, Jr., Jones LG. Gentamicin in the neonatal period. Am J Dis Child 1970;120:524-33. 
17. Pons G, d'Athis P, Rey E, de Lauture D, Richard MO, Badoual J et al. Gentamicin monitoring in neonates. Ther Drug Monit 1988;80:421-7.

18. Edward C, Low DC, Bissenden JG. Gentamicin dosage for the newborn. Lancet 1986;1:508-9.

19. World Health Organization. Management of the child with a serious infection or severe malnutrition: guidelines for care at the first-referral level in developing countries. Geneva: World Health Organization, 2000. 177 p. (WHO/FCH/CAH/00.1).

20. Skopnik H, Heimann G. Once-daily aminoglycoside dosing in full term neonates. Pediatr Infect Dis J 1995;14:71-2.

21. Skopnik H, Wallraf R, Nies B, Tröster K, Heimann G. Pharmacokinetics and antibacterial activity of daily gentamicin. Arch Dis Child 1992;67:57-61.

22. Gresores A, Hall DM, Kawato K, MCartney K, Thureen PJ. A once daily gentamicin dosing regimen for neonates $\geq 34$ weeks postconceptional age. Pediatr Res 1994;35:297A.

23. Grasso S, Meinardi RD, De Carneri I, Tamassai V. New in vitro model to study the effect of antibiotic concentration and rate of elimination on antibacterial activity. Antimicrob Agents Chemother 1987; 13:570-6.

24. Leggett JE, Fantin B, Ebert S, Totsuka K, Vogelman $\mathrm{B}$, Calame W et al. Comparative antibiotic dose-effect relation at several dosing intervals in murine pneumonitis and thigh-infection models. J Infect Dis 1989;159:281-92.

25. Mulhall A, Louvois J, Hurley R. Incidence of potentially toxic concentrations of gentamicin in the neonate. Arch Dis Child 1983;58:897-900.

26. Hindmarsh KW, Nation RL, Williams GL, John E, French JN. Pharmacokinetics of gentamicin in very low birth weight preterm infants. Eur J Clin Pharmacol 1983;24:649-53.

27. Daikos GL, Jackson GG, Lolans VT, Livermore DM. Adaptive resistance to aminoglycoside antibiotics with implications for dosing. J Infect Dis 1990;162:414-20.

28. Heimann G. Renal toxicity of aminoglycosides in the neonatal period. Pediatr Pharmacol (New York) 1983;3:251-7.

29. Moore RD, Smith CR, Lietman PS. Risk factors for the development of auditory toxicity in patients receiving aminoglycosides. J Infect Dis 1984;149:23-30. 